\title{
Estudo da Citometria de Fluxo e de outras Variáveis Prognósticas em Carcinoma Invasivo da Mama
}

Autor: Regina Paula Zambotti

Orientador: Prof. Dr. Laurival A. de Luca

Dissertação apresentada ao curso de Pós-Graduação em Ginecologia e Obstetrícia, Área de Concentração em Ginecologia da Faculdade de Medicina de Botucatu - UNESP, para obtenção do Título de Mestre, em 14/12/98.

Foram estudados 63 Carcinoma da Mama (CM) invasivos, os quais investigamos a correlação do indice DNA, fase S e R.E. com parâmetros clínicos e anátomo-patológicos. Avaliamos: raça, paridade, edema, ulceração, presença de linfonodos palpáveis, mama comprometida e estadiamento. Porém, só foram correlacionados: o indice DNA, fase $\mathrm{S}$ e os RE com a idade e o tamanho do tumor verificado pela clínica. Do ponto de vista anátomo-patológico e imuno-histoquimico correlacionamos: grau histológico, indice mitótico e comprometimento axilar com o indice DNA, fase S e RE Considerando os dados disponiveis em nossa casuística, só foi possivel correlacionarmos o índice DNA, fase $\mathrm{S}$ e o RE com o PLD observamos as seguintes associações estatisticamente significativas: Fase $S$ com: indice mitótico, tamanho do tumor e índice de DNA. Índice de DNA com: índice mitótico e grau histológico. $R E$ com: índice mitótico, grau histológico e idade. Não consideramos relevante a associação entre indice DNA, fase S e RE com o tipo histológico do tumor devido ao pequeno número de casos diferentes do carcinoma ductal invasivo. Portanto, com base em nossa investigação, o índice mitótico e o grau histológico podem contribuir para o valor prognóstico na impossibilidade da realização da CF Porém, a correlação entre os vários parâmetros estudados, contribui com informações mais precisas sobre o prognóstico do CM.

Palavras-chave: Mama: câncer. Câncer: prognóstico.

\section{Avaliação dos Efeitos Vasculares do 17ß - Estradiol sobre as Artérias Uterinas de mulheres na pós-menopausa através da Dopplervelocimetria Transvaginal Colorida}

Autor: João Pedro Junqueira Caetano

Orientador: Prof. Dr. Aroldo Fernando Camargos

Tese de Mestrado apresentada ao Departamento de Ginecologia e Obstetrícia da Faculdade de Medicina da Universidade Federal de Minas Gerais, em 5/12/97.

Um estudo experimental do tipo triplo-cego randomizado foi realizado, no período de fevereiro a julho de 1997 com 64 pacientes pós-menopausadas com o objetivo de se estudar os efeitos da estrogenioterapia (17 $\beta$-estradiol) por via transdérmica sobre a resistência vascular das artérias uterinas medida pela Dopplerfluxometria Transvaginal Colorida (DTC). O protocolo de estudo foi desenhado segundo as normas do "Good Clinical Practice". As pacientes foram divididas, através da tabela de alocação aleatória, em dois grupos: Grupo I - casos, contendo 30 pacientes que receberam $17 \beta$-estradiol através da via transdérmica; e Grupo II - controle contendo 31 pacientes, que receberam placebo através da via transdérmica. A média do Índice de Pulsatilidade (IP) no Grupo I - casos ANTES do tratamento foi de 3,41 \pm 0,81 (média \pm d.p.) e DEPOIS foi de 2,37 $\pm 0,66$ (média \pm d.p.), apresentando uma diferença média antes/depois de 1,04 \pm 0,82 (média \pm d.p.), o que representou uma queda de $30,5 \%$ nos valores médios do IP antes do tratamento. A análise estatística revelou uma diferença estatística importante, com um valor de $\mathrm{p}$ estatisticamente significante $(\mathrm{p}<0,0001)$ para os valores antes e depois, no grupo que fez uso da medicação (17ß-estradiol). Concluímos que a terapia com $17 \beta$-estradiol por via transdérmica leva a uma diminuição da resistência vascular das artérias uterinas em pacientes na pósmenopausa, evidenciando um efeito vasodilatador dos estrogênios.

Palavras-chave: Estrogênios. Menopausa. Terapia de reposição hormonal. 